\title{
Requirements Engineering Related Usability Techniques Adopted in Agile Development Processes
}

\author{
Daniel A. Magües \\ Escuela Politécnica Superior \\ Universidad Autónoma de Madrid \\ Madrid, Spain \\ daniel.magues@estudiante.uam.es
}

\author{
John W. Castro \\ Departamento de Ingeniería Informática \\ y Ciencias de la Computación \\ Universidad de Atacama \\ Copiapó, Chile \\ john.castro@uda.cl
}

\author{
Silvia T. Acuña \\ Escuela Politécnica Superior \\ Universidad Autónoma de Madrid \\ Madrid, Spain \\ silvia.acunna@uam.es
}

\begin{abstract}
Context: Over the last decade there has been a growing interest in the integration of agile software development process (ASDP) and user-centred design (UCD). However, there are no papers that study which usability techniques related to requirements engineering are being adopted in the ASDP, and there are no formalized proposals for their adoption. Objective: Identify which techniques related to requirements engineering activities are being adopted in the ASDP and determine how they are being adopted. Method: We have conducted a systematic mapping study (SMS) to retrieve the literature reporting the application of usability techniques in the ASDP. We analysed these techniques using a catalogue of techniques compiled by software engineering researchers. We then determined the manner in which the techniques that are being used in the ASDP were adopted. Results: The agile community is very much interested in adopting usability techniques. The most used techniques are Personas, contextual inquiry and prototyping. Conclusions: This research offers an overview of the adoption of usability techniques related to requirements engineering in ASDPs and reports how they are being adopted. We found that some of the techniques are being adapted for adoption.
\end{abstract}

Keywords- agile software development; user-centred design; systematic mapping study; usability; usability techniques

\section{INTRODUCTION}

The integration of agile software development processes (ASDP) (for example, XP [1] and SCRUM [2]) and the usercentred design process has been a focus of research over the last few years [3][4][5]. This growing interest is explained by the fact that UCD is useful for understanding the needs of future system users and how the software can provide support for their goals and activities in order to improve usability and user satisfaction with system interaction. However, such features are not usually taken into account during requirements elicitation in the ASDP [3][5]. Usability is a quality attribute of software system use and relies not only on the appearance of the user interface but also on how the user interacts with the system [6].

The ASDP recommends that, instead of collecting all the requirements at the start of the project, they should be elicited during just-in-time cycles for each increment as the software is built [2]. According to some authors, this is a good strategy for handling and prioritizing "emerging requirements" (together with stakeholders) and adapting team workload accordingly
[2][7]. On one hand, in the particular case of SCRUM, the requirements are accommodated in a product backlog as user stories. These user stories are living entities because they are constantly changing [2]. On the other hand, UCD places the user at the centre of requirements analysis, design and evaluation activities in order to improve the usability of the final product [3]. UCD professionals apply UCD techniques and methods as part of a collaborative and iterative process [8][9]. Therefore, UCD professionals and teams enacting the ASDP are potentially well-matched, and their alignment could improve user experiences.

However, the usability requirements elicitation principles and practices applied in agile processes have been found to be wanting [4]. This occurs when, for example, the usability requirements are elicited in situ from customers that have a perfect understanding of the needs of the system but not of the different types of end users. This is an obstacle to the identification of potential usability problems facing novice end users [10][11]. One of the principles of UCD, on the other hand, is to understand all user profiles [11]. Many authors working in the human-computer interaction (HCI) domain claim that UCD professionals have to adapt their mind-set to the agile process [2][12][13][14]. But this is by no means straightforward for two reasons. First, many UCD professionals work as part of teams that are separate from and provide support to the agile development team. Therefore, they have a different culture. Second, many professionals have had to develop their own strategies to align UCD practices with the ASDPs adopted by their organization [15]. Thus, the adaptation of usability techniques and methods is based on the experience of UCD professionals, and many such usability techniques require time and resources that an agile process cannot afford. Additionally, agile processes do not provide any guidelines for such adaptations.

Therefore, there is a need for research into which usability techniques can be adopted in ASDP requirements engineering activities. Some researchers have completed empirical studies [16][17][18], whereas a few have conducted comprehensive literature reviews [4][19] in order to identify the usability techniques that are being adopted in the ASDP. The goal of our research is to ascertain the current state of usability in the ASDP from a broader perspective. In order to analyse the benefits of usability in the ASDP and identify which usability techniques related to the requirements engineering activity are 
being adopted and how, we have conducted a systematic mapping study (SMS) of usability and ASDPs.

The literature on the integration of usability techniques into the ASDP is composed of a set of assorted papers that study different issues related to the topic. We identified two problems from these papers. First, there are not many papers that study the topic as a whole and report the current state of integration [11][19][20]. Second, there are no formalized proposals for adopting usability techniques in the ASDP [18][21][22] that establish guidelines for each adopted technique. Therefore, the research problem addressed in this paper is review the literature in order to identify which usability techniques related to requirements engineering activities are being adopted in the ASDP.

This paper is organized as follows. Section 2 discusses the catalogue of HCI techniques that we used as a baseline for investigating the usability techniques that the agile community is using. Section 3 describes the research method. Section 4 reports the usage of usability techniques related to requirements engineering in ASDPs. Section 5 discusses how the usability techniques have been adopted by the ASDPs. Finally, section 6 reports our conclusions and future work.

\section{BACKGROUND}

In order to find out which techniques are being used in agile development projects to produce usable systems, we first need to identify the universe of HCI techniques. This is far from straightforward. There are a wide range of HCI techniques, where the same technique may be referred to differently depending on the author and there may be more than one variant on the same technique. Fortunately, other software engineering researchers have already taken the trouble to compile a catalogue of HCI techniques [24]. Ferré [24] compiled a list of techniques from the recognized HCI sources. There follows a very brief summary of this catalogue which should help readers to follow the remainder of the paper analysing which usability techniques are used in ASDP and how they are being adopted.

According to Ferré [24], the most representative activities of the HCI process are use context specification, usability specifications, product concept development, prototyping, interaction design, and usability evaluation. Ferré [24] maps these activities (and their respective associated techniques) to SE development stages. HCI activities are in some cases integrated into existing SE activities. For example, the usability specifications activity can be integrated into requirements specification. In other cases, however, further activities that are not usually carried out in a non-user-centred development process, such as interaction design, have to be added. These extra activities will be referred to as usual in the HCI community. HCI activities have been mapped taking into account SE development stages: requirements engineering, design and evaluation. HCI techniques in the catalogue are classified according to the meaning of requirements engineering, design and evaluation for SE. For our research, we only had to consider techniques related to the requirements engineering activity. The HCI activities mapped to the requirements engineering activity are: use context specification, usability specifications, product concept development and prototyping.

\section{RESEARCH METHOD}

We have conducted a SMS [23] to investigate the current state of the integration of agile processes and usability. The electronic databases (DB) used in the SMS were Scopus, ACM Digital Library and IEEE Xplore. The review covers papers published up until 15 October 2015. Fig. 1 illustrates the search string used in the SMS. We used different synonyms to extend the scope of the search. The inclusion criteria of the literature review state that the research papers should mention an issue related to usability and agile development. The search was divided into two stages. During the first stage, we examined the title, keywords and abstract to screen the 409 papers retrieved from all three DBs, of which we selected 172 as possibly relevant papers. Only papers that were written in English and whose abstract or title mentioned an issue related to the integration of agile processes and usability, a topic related to usability engineering or HCI techniques, or a question related to the UCD process were selected. Papers were rejected if they made no mention of anything to do with the integration of agile processes and usability or the UCD process. During the second stage, we read the abstract, introduction and conclusions to determine whether the paper described any type of integration between agile processes and usability through HCI techniques or practices. Finally, as a result of the second stage, we retrieved a total of 31 relevant papers (primary studies).

\begin{tabular}{|c|c|}
\hline $\begin{array}{l}\text { "usability" OR } \\
\text { "usability method" OR } \\
\text { "usability technique" OR } \\
\text { "usability engineering" OR } \\
\text { "usability practice" OR } \\
\text { "user centered design" OR } \\
\text { "user-centered design" OR } \\
\text { "user interaction" OR } \\
\text { "user experience" }\end{array}$ & $\begin{array}{l}\text { "agile development" OR } \\
\text { "agile software development" OR } \\
\text { "agile method" OR } \\
\text { "agile process" OR } \\
\text { "agile project" OR } \\
\text { "agile practice" OR } \\
\text { "extreme programming" OR } \\
\text { "scrum" }\end{array}$ \\
\hline \multicolumn{2}{|c|}{ AND } \\
\hline
\end{tabular}

Figure 1. Keywords used for the search string.

The terms used in the SMS search string are the most commonly used by authors specializing in the field. However, other terms identifying other relevant papers may have been overlooked. Additionally, the papers were analysed and evaluated based on our opinions and experience. This means that other authors may have arrived at different conclusions about the same results.

All three members of the research team helped to define the search strategy. Two researchers designed and ran the searches and extracted the data. Later, the findings were discussed at meetings attended by all team members.

After analysing all the primary studies, we found that practice integration accounts for the adoption of specified HCI techniques. The papers classified as practice integration identify the adoption of usability techniques in the ASDP and vice versa. 
The primary studies that we study in order to analyse the usability techniques adopted in the ASDP refers to practice integration (31 publications). Our reason for selecting this type of integration was that, because no profound process changes are called for, it would, we believe, be more practicable to integrate usability techniques into ASDPs, since this would require neither a major effort to train the teams enacting the ASDP nor additional investment in order to bring new roles into the team. After discussing each paper at meetings attended by all the research team members, we determined which usability techniques have been adopted in the ASDP, outputting the description given by the author. These techniques were analysed by comparing the manner in which the technique was applied in the ASDP with the original recommendation established by the HCI community. It took several rounds to identify these techniques. The process was complicated by the fact that the authors of the primary studies did not use the customary technique names. Therefore, we had to read the paper more thoroughly in order to identify technique to which the authors were referring. Through the description of the techniques adopted in the ASDP, the use of a catalogue of HCI techniques [24][25][26][27] (detailed in Section 4) and consultation with experts, we identified which usability techniques reported in the literature have been adopted in ASDP development projects. An expert in usability techniques participated in this identification process. This process yielded a preliminary classification of the different usability techniques related to requirements engineering adopted in ASDPs.

We then analysed how the usability techniques were adopted in ASDP requirements engineering activities. As a result of this analysis, we found that some techniques were adopted as per HCI recommendations and others needed adaptation. For each of the techniques adopted by the ASDP, we identified the adaptations made (some are discussed in Section 4). This turned out to be one of the most complex processes because of the sheer number of techniques and the fact that the primary studies did not compare the technique that they described with HCI recommendations. This comparison was necessary in order to be able to identify the adaptations made to the techniques.

\section{USE OF HCI TECHNIQUES RELATED TO ASDP REQUIREMENTS ENGINEERING}

We have found that the agile community has adopted a number of usability techniques in development projects. We have classified the adopted usability techniques into two groups. The first group includes all the techniques that have been adopted as is, that is, have been applied as recommended by HCI. The second group includes the techniques that have had to be adapted for adoption. In order to identify the techniques adopted in ASDPs, we examined the papers in the practice integration group. We read each paper carefully to identify the names of all the techniques reported by the author and their respective description. Note that some authors report the adoption of more than one usability technique. After reading their respective descriptions, we then classified each technique adopted in ASDPs according to the HCI technique catalogue [24]. This task was carried out in conjunction with experts in the area as part working sessions aimed at identifying which catalogue techniques had been adopted by
ASDPs. Only the description given by the author of how the technique was adopted was considered for identification purposes. The name given to the technique was omitted because of the possibility of it distorting our classification. Generally speaking, the authors are not expert technique catalogue users. Table I summarizes the number of HCI techniques related to the requirements activity adopted in ASDPs. This summary includes the total number of existing techniques (according to the catalogue used [24]) and the percentage of such techniques that we identified as having been adopted by the agile community. Note that some of the techniques and their respective description required a more thorough analysis in order to identify the HCI technique to which they mapped in the catalogue.

TABLE I. Percentage of HCI TeChNiques Adopted IN ASDPS

\begin{tabular}{|c|c|c|c|}
\hline \multicolumn{2}{|c|}{ SE Development Stage } & $\begin{array}{c}\text { No. of HCI } \\
\text { Techniques } \\
\text { (following [24]) }\end{array}$ & $\begin{array}{c}\text { No. of } \\
\text { Techniques } \\
\text { Adopted by }\end{array}$ \\
\hline \multirow{3}{*}{$\begin{array}{l}\text { Requirements } \\
\text { Engineering }\end{array}$} & $\begin{array}{l}\text { Requirements } \\
\text { Elicitation and } \\
\text { Analysis }\end{array}$ & 25 & $13(52.00 \%)$ \\
\hline & $\begin{array}{l}\text { Requirements } \\
\text { Specification }\end{array}$ & 1 & $0(0.00 \%)$ \\
\hline & $\begin{array}{l}\text { Requirements } \\
\text { Validation }\end{array}$ & 7 & $3(42.86 \%)$ \\
\hline
\end{tabular}

Additionally, the HCI technique catalogue had to be expanded because ASDPs have adopted techniques listed in the catalogue, which, however, they have applied in SE development stages other than those specified in the HCI catalogue. For example, Losada et al. [28][29] propose designing questionnaires, surveys and interviews as part of the requirements elicitation activities.

We found that ASDPs have adopted 52\% of the usability techniques related to requirements engineering. Of this group, Personas is the most used technique, followed by contextual inquiry and prototyping. Table II summarizes the HCI techniques related to requirements engineering activities adopted by ASDPs. For each technique, we specify the SE development stage to which it is related, a generic technique name, the name given by different authors in the HCI literature (the variants of the generic technique in italics), the name used by the ASDP authors, the references and the level of adoption (as is or with modifications). Note that, for reasons of space, Table II does not list the usability techniques related to requirements engineering that have not been adopted by the agile community in its development projects.

\section{V.RESULTS AND DISCUSSION}

In this section, we discuss how ASDPs have adopted usability techniques. Note that all mentions of usability techniques adopted in ASDP development projects throughout this research paper refer to techniques that have been adopted and then reported in the literature. We have classified each and every one of the usability techniques that have been adopted by ASDP developments. They have been classified according to a 
HCI technique catalogue [24], analysing how the technique was applied. We have found that techniques are being adopted in two ways: usability techniques applied as is (i.e., the technique has been applied as recommended by $\mathrm{HCI}$ ) and techniques that have been adapted (i.e., the technique has been somehow modified for application within agile developments).

The usability techniques adopted in ASDP requirements engineering activities are: contextual inquiry, ethnographical observation, card sorting, Personas, questionnaires, surveys and interviews, essential use cases, task scenarios, task sorting, scenarios and storyboards, prototyping, inspections, cognitive walkthroughs, and evaluation by experts. Contextual inquiry, Personas and prototyping can be singled out as the most commonplace techniques. We have found that some techniques (e.g., contextual inquiry) have been adopted in agile developments both as is and with modifications. The type of adoption (as is, with modifications) depends on the particular features and resources of each project.

TABLE II. HCI TECNIQUES RELATED TO SE REQUIREMENTS ENGINEERING ACTIVITIES ADOPTED IN ASDPS

\begin{tabular}{|c|c|c|c|c|c|c|}
\hline \multicolumn{2}{|c|}{ SE Development Stage } & $\begin{array}{c}\text { Generic } \\
\text { Technique Name }\end{array}$ & $\begin{array}{c}\text { Technique Name Given by HCI } \\
\text { Authors }\end{array}$ & Name Used by ASDP Authors & Ref. & Application Type \\
\hline \multirow{41}{*}{$\begin{array}{l}\text { Requirements } \\
\text { Elicitation and } \\
\text { Analysis }\end{array}$} & & \multirow{7}{*}{ Contextual Inquiry } & \multirow{3}{*}{ Contextual Inquiry } & Contextual analysis & [32] & As Is \\
\hline & & & & Context of use & [34] & As Is \\
\hline & & & & Contexts of use & [31] & As Is \\
\hline & & & \multirow{4}{*}{ Contextual Interviews } & Contextual inquiry & [30] & With modifications \\
\hline & & & & Context inquiry & {$[16]$} & As Is \\
\hline & & & & Contextual inquiry & [35] & As Is \\
\hline & & & & Contextual Inquiry & [36] & As Is \\
\hline & & \multirow{3}{*}{$\begin{array}{l}\text { Ethnographical } \\
\text { Observation }\end{array}$} & Ethnography & Ethnographic research & {$[16]$} & As Is \\
\hline & & & \multirow{2}{*}{ Ethnographical Observation } & Observation & [28] & As Is \\
\hline & & & & Observation & [29] & As Is \\
\hline & & \multirow{2}{*}{ Card Sorting } & \multirow{2}{*}{ Card Sorting } & Card sorting & {$[10]$} & With modifications \\
\hline & & & & Card sorting & [25] & With modifications \\
\hline & \multirow{13}{*}{ User Analysis } & \multirow{9}{*}{ Personas } & \multirow{9}{*}{ Personas } & Personas & [16] & As Is \\
\hline & & & & Personas & {$[27]$} & With modifications \\
\hline & & & & Personas & [37] & With modifications \\
\hline & & & & Personas & [31] & As Is \\
\hline & & & & Lightweight personas & [38] & With modifications \\
\hline & & & & Personas & [33] & With modifications \\
\hline & & & & Persona & [39] & As Is \\
\hline & & & & Persona & [36] & As Is \\
\hline & & & & Extreme personas & {$[40]$} & With modifications \\
\hline & & \multirow{4}{*}{$\begin{array}{l}\text { Questionnaires, } \\
\text { Surveys and } \\
\text { Interviews }\end{array}$} & \multirow{4}{*}{$\begin{array}{l}\text { Questionnaires, Surveys and } \\
\text { Interviews }\end{array}$} & Questionnaires & [29] & As Is \\
\hline & & & & Interviews & [29] & As Is \\
\hline & & & & Questionnaires & {$[28]$} & As Is \\
\hline & & & & Interviews & {$[28]$} & As Is \\
\hline & Task Analysis & $\begin{array}{l}\text { Essential Use } \\
\text { Cases }\end{array}$ & Essential Use Cases & Essential use cases & {$[34]$} & As Is \\
\hline & \multirow{9}{*}{$\begin{array}{l}\text { Develop Product } \\
\text { Concept }\end{array}$} & \multirow{3}{*}{ Task Scenarios } & \multirow{3}{*}{ Task Scenarios } & Usability user stories & {$[30]$} & With modifications \\
\hline & & & & Usability user stories & [31] & As Is \\
\hline & & & & Usability user stories & [43] & With modifications \\
\hline & & Task Sorting & Task Sorting & Task models & [30] & With modifications \\
\hline & & \multirow{5}{*}{$\begin{array}{l}\text { Scenarios and } \\
\text { Storyboards }\end{array}$} & \multirow{5}{*}{ Scenarios } & Scenario based descriptions & {$[34]$} & As Is \\
\hline & & & & Scenarios & {$[10]$} & With modifications \\
\hline & & & & Scenario based approaches & {$[38]$} & As Is \\
\hline & & & & User scenarios & {$[33]$} & With modifications \\
\hline & & & & Scenarios & {$[25]$} & With modifications \\
\hline & \multirow{6}{*}{ Prototyping } & \multirow{6}{*}{ Prototyping } & \multirow{3}{*}{ Prototyping } & Prototypes & {$[29]$} & As Is \\
\hline & & & & Prototypes & {$[28]$} & As Is \\
\hline & & & & Prototypes & {$[26]$} & As Is \\
\hline & & & Paper Prototypes & Paper prototypes & [31] & As Is \\
\hline & & & Scripted Prototypes & Mock-ups and prototypes & [34] & As Is \\
\hline & & & Wizard of Oz Prototypes & Wizard of Oz testing & [41] & With modifications \\
\hline \multirow{3}{*}{\multicolumn{2}{|c|}{ Requirements Validation }} & Inspections & Collaborative Inspections & Usability inspection evaluations & {$[42]$} & With modifications \\
\hline & & $\begin{array}{l}\text { Cognitive } \\
\text { Walkthrough } \\
\end{array}$ & Cognitive Walkthrough & Informal cognitive walkthrough & {$[17]$} & With modifications \\
\hline & & $\begin{array}{l}\text { Evaluation by } \\
\text { Experts }\end{array}$ & Evaluation by Experts & Peer review & [42] & With modifications \\
\hline
\end{tabular}


As mentioned above, we found that some usability techniques are being adopted thanks to adaptations. For example, the HCI discipline stipulates that, in order to apply contextual inquiry, all the people involved in applying the technique (developers and users) must have previous training and the team must participate in the multidisciplinary meeting from beginning to end. However, agile team members generally do not have previous knowledge of applying usability techniques and developers have limited time and work to a tight schedule. We have found that, in order to solve these two problems, Beyer et al. [30] adapt contextual inquiry in two ways. First, the user interface team compensates for the training gaps of the other participants. Second, due to agile development time constraints, developers are not involved until the end of the multidisciplinary meeting so as not to affect team work in the preceding sprint.

The contextual inquiry technique has also been adopted as is. This technique has been used at the start of agile projects because it is capable of identifying users, their backgrounds, their motivations, their responsibilities and their roles [31]. Besides, it also yields enough information to generate the best possible upfront design and thus conforms to ASDP just-intime analysis practices [32].

The most often used technique, Personas, has been adopted with modifications. We have found that there is a tendency to apply the technique iteratively as proposed by ASDPs developing the model as necessary for the functionality under development [33]. It has also been applied as is and used as a means of communication with developers to identify the different user types and understand their needs and perspectives [31].

The prototyping technique has been adopted as is in most cases because it is considered to be a lightweight technique for use in ASDPs. Low-fidelity paper prototypes, which do not require many resources or much time [28], are built in the early and intermediate stages and may be submitted to users for evaluation [34].

\section{CONCLUSIONS}

In this research we determined which usability techniques are being adopted in agile development projects and looked at how they are being adopted. Additionally, we identified how some ASDPs are adapting the techniques for adoption. The most commonly used techniques are Personas, contextual inquiry and prototyping. On one hand, many HCI techniques related to requirements elicitation and analysis are naturally lightweight (e.g. paper prototypes), whereas others require adaptations to be able to be adopted in some agile projects (e.g. Personas). However, these are neither widespread nor prescriptive adaptations. On the other hand, as the process involves users, the activities need to be conducted in a methodical and structured manner. This can be achieved by adopting usability techniques, but ASDPs do not provide any guidelines for adoption.

There are three main ASDP adaptations of HCI techniques. The first is to conduct user testing outside laboratories. The second is to divide persona creation into several iterative cycles. The third is to abridge heuristic checklists and substitute agile team roles such as product owner for experts in the heuristic evaluation technique.

Our results suggest that the agile development community is starting to adopt usability techniques in its development projects. However, a general, prescriptive and systematic proposal enabling agile development teams to adopt usability techniques in their development projects is missing in the literature. On this ground, there is a need for further research into this issue.

As future research, we intend to extend the paper searches to cover other databases, like, for example, SpringerLink and ScienceDirect. The aim is to increase the number of relevant papers retrieved, as we have found that there is a lot of interest in this topic within the scientific community.

\section{ACKNOWLEDGMENT}

This research was funded by the Spanish Ministry of Education, Culture and Sports FLEXOR and "Realizando Experimentos en la Industria del Software: Comprensión del Paso de Laboratorio a la Realidad" projects (TIN2014-52129-R and TIN2014-60490-P, respectively) and the eMadrid-CM "Investigación y Desarrollo de Tecnologías Educativas en la Comunidad de Madrid" project (S2013/ICE-2715).

\section{REFERENCES}

[1] K. Beck, "Embracing change with extreme programming", Computer, vol. 32, no 10, 1999, pp. 70-77.

[2] M. Cohn, Succeeding with Agile: Software Development Using Scrum, Pearson Education, 2009.

[3] S. Humayoun, Y. Dubinsky and T. Catarci, "A three-fold integration framework to incorporate user-centered design into agile software development", Lecture Notes in Computer Science (including subseries Lecture Notes in Artificial Intelligence and Lecture Notes in Bioinformatics), vol. 6776 LNCS, 2011, pp. 55-64.

[4] D. Salah, R. Paige and P. Cairns, "A systematic literature review for Agile development processes and user centred design integration", in proceedings of the ACM International Conference, 2014, pp. 5-14.

[5] A. Wale-Kolade, P. Nielsen and T. Päivärinta, "Integrating usability practices into agile development: A case study", in proceedings of the 23rd International Conference on Information Systems Development, 2014, pp. 337-347.

[6] N. Juristo, A. Moreno and M. Sanchez-Segura, "Guidelines for Eliciting Usability Functionalities", IEEE Transactions on Software Engineering, vol. 33, n 11, 2007, pp. 744-758.

[7] L. Cao and B. Ramesh, "Agile requirements engineering practices: An empirical study", IEEE Software, vol. 25, n 1, 2008, pp. 60-67.

[8] S. Chamberlain, H. Sharp and N. Maiden, "Towards a framework for integrating agile development and user-centred design", Lecture Notes in Computer Science (including subseries Lecture Notes in Artificial Intelligence and Lecture Notes in Bioinformatics), vol. 4044 LNCS, 2006, pp. 143-153.

[9] D. Fox, J. Sillito and F. Maurer, "Agile methods and user-centered design: How these two methodologies are being successfully integrated in industry", in proceedings of the Agile Conference, 2008, pp. 63-72.

[10] D. Kane, "Finding a place for discount usability engineering in agile development: throwing down the gauntlet", in proceedings of the Agile Development Conference, 2003, pp. 40-46.

[11] O. Sohaib and K. Khan, "Integrating usability engineering and agile software development: A literature review", in proceedings of the International Conference on Computer Design and Applications, 2010, pp. V232-V238. 
[12] J. Barksdale, E. Ragan and D. McCrickard, "Easing team politics in agile usability: A concept mapping approach", in proceedings of the Agile Conference, 2009, pp. 19-25.

[13] D. D. Brown, "Five Agile UX Myths", J. Usability Studies, vol. 8, n 3, 2013, pp. 55-60.

[14] M. Seyam, "Enhancing usability through agility: Pair programming for a practice-oriented integration approach", in proceedings of the 2015 International Conference on Collaboration Technologies and Systems (CTS), 2015, pp. 460-463.

[15] A. Bertholdo, T. Da Silva, C. De O. Melo, F. Kon and M. Silveira, "Agile usability patterns for UCD early stages", Lecture Notes in Computer Science (including subseries Lecture Notes in Artificial Intelligence and Lecture Notes in Bioinformatics), vol. 8517 LNCS, $\mathrm{n}^{\circ}$ 1, 2014, pp. 33-44.

[16] D. Broschinsky and L. Baker, "Using Persona with XP at LANDesk Software, an Avocent Company", in proceedings of the Agile Conference, 2008, pp. 543-548.

[17] V. Grigoreanu and M. Mohanna, "Informal Cognitive Walkthrough (ICW): Paring down and pairing up for an agile world", in proceedings of the Human Factors in Computing Systems, 2013, pp. 3093-3096.

[18] P. Hodgetts, "Experiences integrating sophisticated user experience design practices into Agile processes", in proceedings of the Agile Conference, 2005, pp. 235-242.

[19] M. Brhel, H. Meth, A. Maedche and K. Werder, "Exploring principles of user-centered agile software development: A literature review", Information and Software Technology, vol. 61, 2015, pp. 163-181.

[20] T. Da Silva, A. Martin, F. Maurer and M. Silveira, "User-centered design and agile methods: A systematic review", in proceedings of the Agile Conference, 2011, pp. 77-86.

[21] J. Ferreira, J. Noble and R. Biddle, "Interaction designers on eXtreme Programming teams: Two case studies from the real world", in proceedings of the 5th New Zealand Computer Science Research Student Conference, 2007, pp. 1-8.

[22] Z. Hussain, H. Milchrahm, S. Shahzad, W. Slany, M. Tscheligi and P. Wolkerstorfer, "Integration of extreme programming and user-centered design: Lessons learned", Lecture Notes in Business Information Processing, vol. 31 LNBIP, 2009, pp. 174-179.

[23] K. Petersen, R. Feldt, S. Mujtaba and M. Mattsson, "Systematic Mapping Studies in Software Engineering", in proceedings of the 12th International Conference on Evaluation and Assessment in Software Engineering, 2008, pp. 71-80.

[24] X. Ferré, Marco de Integración de la Usabilidad en el Proceso de Desarrollo Software, 2005.

[25] O. Sohaib and K. Khan, "Incorporating discount usability in extreme programming", International Journal of Software Engineering and its Applications, vol. 5, $\mathrm{n}^{\mathrm{o}}$ 1, 2011, pp. 51-62.

[26] ̊̊. Cajander, M. Larusdottir and J. Gulliksen, "Existing but not explicit The user perspective in scrum projects in practice", Lecture Notes in Computer Science (including subseries Lecture Notes in Artificial Intelligence and Lecture Notes in Bioinformatics), vol. 8119 LNCS, $\mathrm{n}^{\circ}$ 3, 2013, pp. 762-779.

[27] L. Caballero, A. Moreno and A. Seffah, "Persona as a Tool to Involving Human in Agile Methods: Contributions from HCI and Marketing", Lecture Notes in Computer Science (including subseries Lecture Notes in Artificial Intelligence and Lecture Notes in Bioinformatics) 5th IFIP WG 13.2 International Conference, HCSE 2014, vol. 8742, 2014, pp. 283-290.

[28] B. Losada, M. Urretavizcaya, J.-M. López and I. Fernández-Castro, "Applying usability engineering in InterMod agile development methodology. A case study in a mobile application", Journal of Universal Computer Science, vol. 19, no 8, 2013, pp. 1046-1065.

[29] B. Losada, M. Urretavizcaya, J.-M. López-Gil and I. Fernández-Castro, "Combining InterMod agile methodology with usability engineering in a mobile application development", in proceedings of the ACM International Conference, 2012, pp. 39:1-39:8.

[30] H. Beyer, K. Holtzblatt and L. Baker, "An agile customer-centered method: Rapid contextual design", Lecture Notes in Computer Science (including subseries Lecture Notes in Artificial Intelligence and Lecture Notes in Bioinformatics), vol. 3134, 2004, pp. 50-59.

[31] W. Hudson, "Adopting User-Centered Design within an Agile Process: A Conversation", Cutter IT Journal, vol. 16, nº 10, 2003, pp. 5-12.

[32] Adikari, C. McDonald and J. Campbell, "Little design up-front: A design science approach to integrating usability into agile requirements engineering", Lecture Notes in Computer Science (including subseries Lecture Notes in Artificial Intelligence and Lecture Notes in Bioinformatics), vol. 5610 LNCS, $\mathrm{n}^{\circ}$ 1, 2009, pp. 549-558.

[33] M. Najafi and L. Toyoshiba, "Two case studies of user experience design and agile development", in proceedings of the Agile Conference, 2008, pp. 531-536S.

[34] M. Düchting, D. Zimmermann and K. Nebe, "Incorporating user centered requirement engineering into agile software development", Lecture Notes in Computer Science (including subseries Lecture Notes in Artificial Intelligence and Lecture Notes in Bioinformatics), vol. 4550 LNCS, $n^{\circ} 1,2007$, pp. 58-67.

[35] W. Isa, A. Lokman, S. Aris, M. Aziz, J. Taslim, M. Manaf and R. Sulaiman, "Engineering rural informatics using agile user centered design", in proceedings of the 2nd International Conference on Information and Communication Technology, 2014, pp. 367-372.

[36] W. Rahim, W. Isa, A. Lokman, N. Taharim and N. Wahid, "Engineering m-learning using agile user-centered design", in proceedings of the 8th International Conference on Next Generation Mobile Applications, Services and Technologies, 2014, pp. 60-65.

[37] J. Haikara, "Usability in agile software development: Extending the interaction design process with personas approach", Lecture Notes in Computer Science (including subseries Lecture Notes in Artificial Intelligence and Lecture Notes in Bioinformatics), vol. 4536 LNCS, 2007, pp. 153-156.

[38] J. Kollmann, H. Sharp and A. Blandford, "The importance of identity and vision to user experience designers on agile projects", in proceedings of the Agile Conference, 2009, pp. 11-18.

[39] Y. Nakao, M. Moriguchi and H. Noda, "Using agile software development methods to support human-centered design", NEC Technical Journal, vol. 8, ${ }^{\circ}$ 3, 2014, pp. 37-40.

[40] P. Wolkerstorfer, M. Tscheligi, R. Sefelin, H. Milchrahm, Z. Hussain, M. Lechner and S. Shahzad, "Probing an agile usability process", in proceedings of the Conference on Human Factors in Computing Systems, 2008, pp. 2151-2157.

[41] G. Meszaro and J. Aston, "Adding usability testing to an agile project", in proceedings of the Agile Conference, 2006, pp. 289-294.

[42] T. Da Silva, M. Silveira and F. Maurer, "Usability evaluation practices within agile development", in proceedings of the Annual Hawaii International Conference on System Sciences, 2015, pp. 5133-5142.

[43] A. Moreno and A. Yagüe, "Agile user stories enriched with usability", Lecture Notes in Business Information Processing, vol. 111 LNBIP, 2012, pp. 168-176.. 